\title{
REALIDADES SITUADAS EN TIEMPOS DE COVID-19: PUEBLOS INDÍGENAS AMAZÓNICOS FRENTE A LA PANDEMIA Y EL EXTRACTIVISMO EN EL ECUADOR
}

\section{REALITIES SITUATED IN COVID-19 TIMES: INDIGENOUS AMAZON PEOPLES FACING PANDEMICS AND EXTRACTIVISM IN ECUADOR}

\author{
MARÍA JNÉS RIVADENEIRA \\ Universitat de Girona \\ mariaines.rivadeneira@gmail.com \\ MARCO APARICIO WILHELMI \\ Universitat de Girona \\ marco.aparicio@udg.edu
}

Fecha de recepción : 17 de octubre de 2020 / Fecha de aceptación: 25 de noviembre de 2020

RESUMEN: En el presente trabajo se expone cómo el Estado-nación aplicó un modelo homogeneizante de atención en la emergencia sanitaria que desconoció, en un inicio, las particularidades de la población, la situación geográfica, la provisión y acceso de servicios básicos (alimentación y agua segura) y de salud, las necesidades de acuerdo a las culturas, así como la protección específica sobre diferentes formas de violencia en los territorios y hacia las mujeres en espacios familiares y/o comunitarios. Se observa a lo largo del artículo una discusión sobre el centralismo y verticalismo institucional y el ejercicio de la autodeterminación de los pueblos indígenas en tiempos de emergencia; así como la configuración de respuestas universalizantes que desconocen la diversidad y serias dificultades para materializar el Estado Plurinacional en Ecuador.

Con sus matices y diferencias, los pueblos amazónicos demandan en tiempos de pandemia garantía de sus derechos, el respeto a sus formas tradicionales de 
vida, una atención de salud culturalmente apropiada, la defensa del territorio contra el extractivismo y la desposesión.

RESUM: En el present treball s'exposa com l'Estat-nació ha aplicat un model homogeneïtzador d'atenció a l'emergència sanitària que ha desconegut, en un inici, les particularitats de la població, la situació geogràfica, la provisió i accés de serveis bàsics (alimentació i aigua segura) i de salut, les necessitats d'acord a les cultures, així com la protecció específica sobre diferents formes de violència en els territoris i en especial vers les dones en espais familiars i/o comunitaris. S'observa al llarg de l'article una discussió sobre el centralisme i verticalisme institucional i l'exercici de l'autodeterminació dels pobles indígenes en temps d'emergència; així com la configuració de respostes universalistes que desconeixen la diversitat i demostren dificultats per materialitzar l'Estat Plurinacional a l'Equador.

Amb els seus matisos i diferències, els pobles amazònics demanen en temps de pandèmia garantia dels seus drets, el respecte a les seves formes tradicionals de vida, una atenció de salut culturalment apropiada, la defensa del territori contra el extractivisme i la despossessió.

ABSTRACT: This paper shows how the nation-state applied a homogenizing model of care in the health emergency that initially ignored the particularities of the population, the geographical situation, the provision and access to basic services (food and safe water) and health, the needs according to the cultures, as well as the specific protection against different forms of violence in the territories and towards women in family and / or community spaces. Throughout the article, we observe a discussion on institutional centralism and the exercise of self-determination by indigenous peoples in times of emergency; as well as the configuration of universalizing responses that ignore diversity and its difficulties in materializing the Plurinational State.

With their nuances and differences, the Amazonian peoples demand in times of pandemic guarantee to their specific rights, respect for their traditional ways of 
life, culturally appropriate health care, defense of the territory against extractivism and dispossession.

PALABRAS CLAVE: Pueblos indígenas - Amazonía - Derechos colectivos Autonomía - Autodeterminación - Pandemia

PARAULES CLAU: Pobles indígenes - Amazònia - Drets col-lectius Autonomia - Autodeterminació - Pandèmia

KEY WORDS: Indigenous peoples - Amazonia - Collective rights - Autonomy Self-determination - Pandemic

SUMARIO: I. INTRODUCCIÓN; METODOLOGÍA Y BASES CONCEPTUALES; III. LA CRISIS DE LA COVID-19 HACIA DENTRO Y HACIA FUERA DE LAS AUTONOMÍAS INDÍGENAS; IV. COVID-19 Y SISTEMAS DE SALUD PROPIOS; V. SOBERANÍA INDÍGENA FRENTE A DEPENDENCIAS MÚLTIPLES Y ESTRUCTURALES. 1. Derechos colectivos y 'brecha de la implementación'. 2. Centralismo y homogeneidad estatal vs. multi-gobernanza desde realidades localmente situadas VI. CONCLUSIONES; VII. BIBLIOGRAFÍA

\section{INTRODUCCIÓN}

La Amazonía se ha caracterizado, en tanto que territorio internacional en disputa, por una política de "fronteras vivas". Esto se vio reflejado en la concepción de "tierras baldías" promovida por la dictadura brasileña de mediados de siglo XX en la que se expresó la idea de "Tierra sin gente para Gente sin tierra". A través de esta premisa, se impulsaron las medidas de colonización de la selva en toda la Amazonía andina. A su vez, con esta política se dio paso a la expansión de fronteras extractivas de la mano de una economía de mercado y una cultura de asimilación y violencia hacia los pueblos indígenas amazónicos configurando la noción de "sociedades de frontera"1. En Ecuador, la

\footnotetext{
1 Víctor A. López, Fernando Espíndola,Juan Calles, Janette Ulloa, "Atlas: Amazonía Ecuatoriana Bajo Presión", en EcoCiencia. Quito-Ecuador, 2013.
} 
consolidación como zona de extracción de materias primas se da a partir de 1967 con la explotación y transporte de crudo en el nororiente.

Con 6 provincias y la presencia de 10 nacionalidades indígenas ancestrales (Achuar, Andwa, Cofán, Kichwa, Siekopia, Siona, Shiwiar, Shuar, Waorani, Sapara), junto con dos pueblos en aislamiento voluntario (Tagaeri y Taromenane), el territorio tiene una población mayormente rural con un total de 245.014 de personas autoidentificadas como indígenas (Censo de Población, INEC 2010). La Región Amazónica Ecuatoriana (RAE) según el Fondo Mundial para la Naturaleza (WWF, por sus siglas en inglés) sufre de presiones y amenazas sobre las poblaciones y ecosistemas asociadas a políticas para el acceso y control del espacio, sus recursos y poblaciones, así como a las actividades extractivas (petróleo, minería, madera, caucho, biodiversidad y conocimientos tradicionales), pobreza, minifundio ${ }^{2}$, deterioro ambiental y violencia $^{3}$ con una especial incidencia en los cuerpos de las mujeres. En Ecuador 65 de cada 100 mujeres han experimentado algún tipo de violencia a lo largo de su vida; en zonas rurales son 62 de cada 100 y en mujeres indígenas 64 de cada $100 .^{4}$

En el presente artículo se recogen las diferentes acciones y demandas presentadas por los pueblos indígenas amazónicos durante la pandemia provocada por la enfermedad de la COVID-19. Alrededor de los acontecimientos se da una discusión sobre los siguientes ejes: La crisis de la COVID-19 hacia dentro y hacia afuera de las autonomías indígenas; soberanía indígena frente a dependencias múltiples y estructurales; COVID-19 y sistemas de salud "propios";

2 Tierras dedicadas a la agricultura convencional, segmentada y parcializada, que responde a un sistema productivo de carácter artificial, la fragmentación y el uso intensivo de la tierra. La agricultura convencional, incluyendo la ganadería, es la actividad que ha generado mayores pérdidas de hábitat natural en la Amazonía en las últimas décadas. Esto ha desatado graves transformaciones en el uso del suelo de sus bosques.

${ }^{3}$ Charity, S., Nigel Dudley, Oliveira, D. and Sue Stolton (editores), Living Amazon Report 2016: A regional approach to conservation in the Amazon, WWF Living Amazon Initiative. Brasília - Quito, 2016.

4 Instituto Nacional de Estadísticas y Censos del Ecuador, INEC. Encuesta nacional sobre relaciones familiares y violencia de género contra las mujeres, 2019. 
$\mathrm{y}$, centralismo y homogeneidad estatal vs. multi-gobernanza desde realidades localmente situadas. Con este debate se plantea una lectura desde la Sociología Jurídica sobre la disputa entre el centralismo y la autonomía de los pueblos indígenas, el predominio de un modelo económico de acumulación, despojo y explotación de los recursos limitados en una de las zonas más megadiversas del planeta y con una alta diversidad lingüística y cultural, así como una especial vulnerabilidad por factores de estrés externos, condiciones de vulnerabilidad propias de territorios alejados de los polos de concentración poblacional y por formas de vida tradicional que se encuentran en permanente amenaza.

Entre los principales hallazgos, como se verá a continuación, podemos avanzar que las respuestas estatales para enfrentar la pandemia de la enfermedad provocada por el COVID-19 siguen el patrón de un sistema mono-cultural y jerárquico de reproducción de conocimientos. La organización del sistema de salud pública, la gestión de la seguridad, movilidad y coordinación política, siguió en un inicio una lógica universalizante que homogeneizó las acciones para todo el territorio y su población. Haciendo una lectura desde los conocimientos situados se señala que en esta estructura, se desconoció la diversidad geográfica, étnica y organizativa del país que constitucionalmente es considerado como un Estado Plurinacional.

En respuesta a la presión de los pueblos indígenas, en especial los amazónicos, se procuró una reorganización de la atención a la emergencia en sus territorios a partir del tercer mes de la pandemia. Sin embargo, el reclamo por una respuesta intercultural a la emergencia sigue siendo un desafío según las dirigencias, por lo que se resalta el debate entre autonomías indígenas y el centralismo político. De todo esto, destaca la organización de las nacionalidades indígenas de la Amazonía para atender las múltiples necesidades de los territorios en salud, defensa del territorio, cobertura de necesidades básicas, conflictos y problemas ambientales, entre otros.

\section{METODOLOGÍA Y BASES CONCEPTUALES}


En un contexto de pandemia por la enfermedad provocada por el COVID-19 se esboza una aproximación a la relación entre derechos colectivos de los pueblos indígenas, vulnerabilidades y autonomía en las respuestas planteadas de manera situada. Se propone una lectura poscolonial (o anticolonial, diría Rivera Cusicanqui ${ }^{5}$ ) que busca despojarse de explicaciones 0 interpretaciones diseñadas desde el norte global o la colonialidad interna, para presentar una narrativa desde la periferia, desde la situación particular de los pueblos indígenas amazónicos, sus visiones, interpretación y respuestas a la situación.

Tomando distancia de ciertas expresiones del postcolonialismo anglosajón, el pensamiento decolonial latinoamericano ha querido trazar la continuidad del proyecto colonial, y ha optado por rechazar una aproximación fundamentalmente cultural ( 0 , en realidad, culturalista) para situar en el centro el análisis económico, las estructuras de la dependencia y la crítica, desde conocimientos situados, al denominado "colonialismo del poder"6. Se cuestionan entonces "las tendencias actuales de las formas institucionales de dominación y en particular del moderno estado-nación"7, las cuales se ven reflejadas en tres elementos: dominación, explotación y conflicto. De ahí una afectación a la estructura de las sociedades y la disputa permanente por su control que se expresan en los recursos y productos del trabajo, el sexo, la autoridad colectiva (o pública), y la subjetividad/intersubjetividad. Los ámbitos de existencia social y su control en permanente disputa forman una compleja estructura de carácter histórico y específico, es decir de un patrón histórico de poder. ${ }^{8}$

\footnotetext{
${ }^{5}$ Considera Silvia Rivera Cusicanqui que lo decolonial es una moda, lo poscolonial un deseo y lo anticolonial una lucha. Dicha consideración se halla recogida en la entrevista publicada por el diario El Salto, publicada el 17 de febrero de 2019. Se pueden encontrar en el siguiente enlace (última visita realizada el 14 de octubre de 2020): https://www.elsaltodiario.com/feminismoposcolonial/silvia-rivera-cusicanqui-producir-pensamiento-cotidiano-pensamiento-indigena (última consulta, 11 de septiembre de 2020).

${ }^{6}$ Aníbal Quijano, Colonialidad del poder, eurocentrismo y América Latina, Gráficas y Servicios. Argentina, 2000.

${ }^{7}$ lbídem

8 lbídem.
} 
Creemos, no obstante, que resulta crucial no abandonar o diluir una necesaria ruptura epistemológica, ruptura que proponen voces como la de Silvia Rivera Cusicanqui. La autora boliviana realiza una crítica, precisamente, a la reproducción de patrones coloniales en las propuestas teóricas 'decoloniales' desarrolladas en América Latina por autores como Quijano o Mignolo. Se refiere la autora a una apropiación de las producciones del Sur global, no sólo en términos de materias primas, sino también de producciones intelectuales. El valor y la legitimación del pensamiento se dan en el marco de un sistema jerárquico de producción de conocimientos que se basan en prácticas de colonización. Así, denuncia Rivera Cusicanqui, que "a través del juego del quién cita a quién, se estructuran jerarquías y acabamos teniendo que comer, regurgitado, el pensamiento descolonizador que las poblaciones e intelectuales indígenas de Bolivia, Perú y Ecuador habíamos producido independientemente" ${ }^{\prime \prime}$.

El modelo económico dominante ha implementado un paquete neoliberal en América Latina durante las últimas décadas. Su implementación ha significado, en algunos escenarios, un ejercicio impositivo de medidas que desconocen el carácter situado del conocimiento. ${ }^{10}$ El diseño de políticas y respuestas en escenarios cambiantes, así como en momentos de crisis, responden entonces a modelos diseñados en centros hegemónicos. La hegemonía de la ideología neoliberal se manifiesta en discursos, estrategias y medidas para enfrentar la pandemia, mismas que han desconocido el carácter plural tanto como las necesidades específicas e impactos diferenciados en culturas y territorios, en particular de los pueblos indígenas amazónicos.

\footnotetext{
9 Silvia Rivera Cusicanqui, Ch'ixinakak utxiwa: una reflexión sobre prácticas y discursos descolonizadores. Tinta Limón Ediciones, Buenos Aires, 2010, p. 66. En semejantes términos se expresa Ramón Grosfoguel, "Del extractivismo económico al extractivismo epistémico y al extractivismo ontológico: una forma destructiva de conocer, ser y estar en el mundo", en Tabula Rasa, núm. 24, enero-junio, Universidad Colegio Mayor de Cundinamarca-Bogotá, Colombia, 2016, p. 123-143.

${ }^{10}$ Roberto H. Esposto y Sergio Holas, "Rodolfo Kusch: hacia una condición postcolonial pensada desde categorías epistemológicas situadas”, en Dissidences, 1, 2008.
} 
Estas consideraciones son relevantes en el contexto del análisis del impacto de la pandemia en los territorios habitados por los pueblos indígenas porque la comprensión misma del fenómeno y las respuestas que se ofrecen desde el Estado están atravesadas por una aproximación monocultural. Así, las medidas frente a la expansión del virus expresan la incapacidad, si no directamente el consciente rechazo, de integrar lecturas diversas, fruto de procesos de diálogo intercultural. Para que exista dicho diálogo debe asegurarse, en primer lugar, un reconocimiento de la igual dignidad entre culturas, algo presente en el plano constitucional para el caso de Ecuador (Constitución de 2008), pero que hasta el momento no ha logrado instalarse a través de una transformación cultural, epistémica. Los momentos de excepcionalidad, de emergencia, suelen visibilizar los resortes, los mecanismos más asentados del comportamiento, institucional en este caso.

En la teoría feminista decolonial se habla de la "violencia epistémica" para explicar la existencia de una "colonialidad del saber". Se problematiza los criterios, cánones y genealogías mediante los cuales desde Occidente se producen ciertos conocimientos mientras otros son invisibilizados. ${ }^{11}$ Desde la profunda asimetría de las posiciones de diálogo -que llegan a invalidarlo- y a partir del peso de lecturas dominantes se han construido representaciones que excluyen o estigmatizan a las culturas indígenas, a las mujeres, a sus luchas. De estas estrategias surgen las relaciones de poder colonial, del despojo, la opresión y la violencia en territorios, tradiciones y conocimientos. La violencia epistémica viene a ser, la circulación de teorías y pensamientos en detrimento de otras.

A partir de las directrices de la la Organización de la Salud (OMS) se identifica que las respuestas nacionales/locales, invisibilizan las necesidades de diferentes identidades de origen, etnia, género, edad y situación de movilidad humana. $\mathrm{Si}$ bien se hace referencia al marco normativo, los espacios de participación y

11 Lola Sánchez, "Difracciones de género y traducción: hacia otra cartografía de saberes situados", Studies, 7(2), 2012, p. 129-143. 
coordinación entre autoridades internacionales, locales e indígenas, sigue siendo un desafío. En tiempos de pandemia, se observa cómo las acciones de lo global a lo local tienen a homogeneizar a la población, desconociendo que cada acción tiene unos impactos distintos de acuerdo a las condiciones de las personas, colectivos o comunidades (Vallejo, Álvarez; 2020) ${ }^{12}$.

Una epistemología situada desde el sur, desde la experiencia del ser indígena, ${ }^{13}$ del ser de la Amazonía permite edificar otras narrativas más allá de la idea del progreso capitalista. Con sus matices y diferencias, los pueblos amazónicos demandan en tiempos de pandemia atención a sus derechos específicos, el respeto a sus formas tradicionales de vida, una atención de salud culturalmente apropiada, la defensa del territorio contra el extractivismo y el despojo.

En el presente trabajo se expone cómo el Estado-nación ha aplicado un modelo homogeneizante de atención en la emergencia sanitaria que ha desconocido, de manera clara en su inicio, las particularidades de la población, la situación geográfica, la provisión y acceso de servicios básicos (alimentación y agua segura) y de salud, las necesidades de acuerdo a las culturas, así como la protección específica sobre diferentes formas de violencia en los territorios y hacia las mujeres en espacios familiares y/o comunitarios. Se observa a lo largo del artículo una discusión sobre el centralismo y verticalismo institucional y el ejercicio de la autodeterminación de los pueblos indígenas en tiempos de emergencia; así como la configuración de respuestas universalizantes que desconocen la diversidad y sus dificultades para materializar al Estado Plurinacional, como consta en la Constitución de la República del Ecuador.

En el estudio se revisan medios digitales de comunicación nacional, comunitarios y de organizaciones tanto indígenas como de fundaciones que

\footnotetext{
12 Ivette Vallejo; Katty Álvarez, "La pandemia del Coronavirus en la Amazonía ecuatoriana: vulnerabilidades y olvido del Estado", Cuadernos de Campo (São Paulo, online), vol. 29, núm. 1, pp.95-110, 2020.

${ }^{13}$ Rodolfo G. Kush, "Una lógica de la negación para comprender a América” y "La negación en el pensamiento popular" en Obras Completas. Tomo II. Editorial Fundación Ross, Rosario, 2000.
} 
acompañan el proceso de defensa de los territorios, de los derechos humanos y colectivos de los pueblos indígenas, y los procesos autonómicos de gobierno. Se consideran publicaciones relevantes a aquellas que recogen las declaraciones de líderes y lideresas indígenas amazónicos, que recuperan sus voces para ubicarlos en primer plano. Esta selección responde a la intención de aproximarnos a los conocimientos situados y las experiencias desde el mundo indígena de la Amazonía ecuatoriana en contraste con el discurso técnico político oficial.

En esta línea, también se hace una lectura de publicaciones de cuentas oficiales de dirigencias indígenas, entrevistas, ruedas de prensa, seminarios y otros espacios en los que se difunde el estado de la situación en las comunidades indígenas amazónicas. Finalmente, se hace una revisión bibliográfica para una comprensión de cómo desde los conocimientos situados y una continua interpelación al Estado, los pueblos indígenas crean estrategias para sobrevivir al olvido, al hambre y al extractivismo.

Debido a las condiciones de confinamiento sostenidas en el Ecuador en el período de la investigación de marzo a septiembre de 2020, el levantamiento de información se realizó vía digital, por lo que se presentan límites en cuanto al acercamiento a los territorios, la implementación de un estudio de corte etnográfico presencial o las limitaciones de gestión documental en audio o imágenes y el acceso a una mayor diversidad de testimonios. Sin embargo, la estrategia de comunicación empleada por las organizaciones indígenas y sus aliados, ha facilitado el seguimiento de la situación en los territorios a diario, con información en tiempo real. Si bien la investigación busca contrastar el ejercicio de las autonomías indígenas frente al centralismo gubernamental en un escenario de emergencia sanitaria, es apenas un acercamiento inicial que debe ser profundizado en cuanto a las condiciones propias de las organizaciones indígenas y la gestión de las dirigencias, tanto como las interacción entre estas y las propias comunidades. 


\section{LA CRISIS DE LA COVID-19 HACIA DENTRO Y HACIA FUERA DE LAS AUTONOMÍAS INDÍGENAS}

Ecuador entró en cuarentena como medida de prevención para evitar la propagación de la COVID-19 el 17 de marzo de 2020. Con corte al 4 de octubre, en la Amazonía Ecuatoriana se registran 4405 personas contagiadas, de las cuales 3059 pertenecen a nacionalidades indígenas, 1306 Kichwa, 1021 Shuar, 367 Waorani, 100 Siona, 84 Achuar, 29 Siekopai, 80 Sapara, 39 Ai Kofán, 14 Shiwiar, 4 Andwa. Un total de 103 fallecidos, de los cuales 49 fueron confirmados como COVID positivo y 54 presentaron sintomatología COVID. Se han realizado a la fecha 8339 pruebas y se tiene una alerta del $60 \%$ de contagio comunitario (CONFENAIE, MSP, octubre 2020).

Las desigualdades persistentes en el orden económico, social y político, son factores determinantes para el acceso a una salud de calidad, oportunidades para el bienestar humano y están directamente relacionadas con las causas de mortalidad temprana y morbilidad de los pueblos indígenas. ${ }^{14}$ De acuerdo a la Organización Internacional del Trabajo, ${ }^{15} 55$ millones de personas indígenas en América Latina y el Caribe son afectadas por la alta vulnerabilidad a la crisis del COVID-19.

Las desigualdades socioeconómicas, sanitarias y ambientales exponen a los pueblos indígenas a los efectos de la pandemia. En la región la tasa de informalidad entre trabajadores indígenas es de $82 \%$ frente a un $54 \%$ de la población general. Las condiciones de precariedad y la informalidad en el trabajo se traducen en la pérdida de medios de vida. ${ }^{16}$ En el informe, "Aplicación del Convenio sobre pueblos indígenas y tribales núm. 169 de la OIT: Hacia un futuro

14 Organización Mundial de la Salud (OMS), "La salud de los pueblos indígenas y afrodescendientes en América Latina", Boletín estadístico, 2013.

15 Organización Internacional del Trabajo (OIT): "55 millones de personas indígenas en América Latina y el Caribe afectadas por alta vulnerabilidad a la crisis de la COVID-19", 2020. Disponible en: https://www.ilo.org/americas/sala-de-prensa/WCMS_746960/lang--es/index.htm (fecha de consulta: 12 de septiembre de 2020).

16 lbídem. 
inclusivo, sostenible y justo" se señala que la población indígena constituye el $8,5 \%$ de la población mundial y son $30 \%$ de personas en pobreza extrema. En la misma línea, del $31 \%$ de personas indígenas que se encuentran en el mercado laboral, no han tenido ninguna formación en comparación con un 12,8 de los no indígenas. ${ }^{17}$ Estas condiciones previas de vulnerabilidad se ven exacerbadas debido al impacto en el empleo en sectores de servicios incluido el trabajo doméstico, la hostelería, turismo, comercio, transporte, manufactura y construcciones, siendo estos espacios en los que laboran personas indígenas (OIT, 2020 a).

El acceso precario a educación y servicios de salud, agua potable y saneamiento, los niveles de desempleo, trabajo informal o mal remunerados, la brecha en el acceso a información y tecnologías, los altos niveles de mortalidad y desnutrición infantil, así como los alarmantes índices de violencia basada en género, son factores que menoscaban las oportunidades para hacer frente a una emergencia sanitaria. De acuerdo a la Organización Mundial de la Salud en Ecuador "La pandemia COVID-19 tiene un mayor impacto en ciertos grupos poblacionales como son los pueblos y nacionalidades indígenas, afroecuatorianos y montubios" 18 .

La crisis económica y social asociada a los impactos de la COVID-19 en la estructura del trabajo, ha generado una "migración inversa" que se caracteriza por el retorno de personas indígenas a sus comunidades ante la falta de medios de subsistencia. Entre otras consecuencias, se observa a partir del segundo mes de la pandemia el incremento de contagios y su ascendente propagación en localidades alejadas; lo que a su vez limita la capacidad de protección de los

17 Organización Internacional del Trabajo (OIT), "Aplicación del Convenio sobre pueblos indígenas y tribales núm. 169 de la OIT: Hacia un futuro inclusivo, sostenible y justo", 2020. Disponible en: https://www.ilo.org/global/publications/books/WCMS_735627/lang--es/index.htm (fecha de consulta: 12 de septiembre de 2020).

${ }_{18}$ Organización Mundial de la Salud (OMS), "Pueblos y nacionalidades en el centro: la estrategia nacional para promocionar la salud en tiempos de pandemia", 2020. Disponible en: https://ecuador.un.org/es/45880-pueblos-y-nacionalidades-en-el-centro-la-estrategia-nacionalpara-promocionar-la-salud-en (fecha de consulta 14 de septiembre de 2020). 
pueblos en aislamiento voluntario. Ante este fenómeno, las medidas socio comunitarias resultan insuficientes frente a las necesidades básicas de las familias (Entrevista Belén Páez, Fundación Pachamama; Mayo-junio) ${ }^{19}$.

La dirigencia de la Confederación de Nacionalidades Indígenas del Ecuador (CONAIE), la Confederación de Nacionalidades Indígenas de la Amazonía Ecuatoriana (CONFENIAE) y las dirigencias de las nacionalidades amazónicas con apoyo de la Coordinadora de las Organizaciones Indígenas de la Cuenca Amazónica (COICA), durante la crisis sanitaria han levantado una campaña propia para responder a la emergencia. Conocedores de la situación de desigualdad y vulnerabilidad en los territorios amazónicos así como de las amenazas externas, el eje más significativo ha sido la comunicación. Mediante redes sociales y una activa distribución de información con traducción a las lenguas originarias, han llegado a la población con datos sobre la situación en tiempo real, medidas sanitarias y uso de medicina tradicional. ${ }^{20}$

Desde cuentas de redes sociales, especialmente Twitter y Facebook, utilizadas mayormente por dirigentes, jóvenes de las nacionalidades indígenas y organizaciones afines, desde el inicio de la pandemia se ha puesto en práctica una estrategia de comunicación directa (Comunicación CONFENAIE, 2020)21. La radio, como medio primordial de comunicación en las comunidades, ha sido la herramienta para informar en las diferentes lenguas sobre medidas de

\footnotetext{
${ }^{19}$ Entrevista a Belén Páez, Directora Fundación Pachamama (Mayo, Junio, 2020)

20 "La medicina tradicional en Ecuador, al igual que en otros países andinos, no es una de corta data. Si bien sus raíces pertenecen a un pasado de más de 10 mil años, su vigencia ha continuado a lo largo de cinco siglos de regímenes coloniales y republicanos. Dicha permanencia ha sido sostenida por los pueblos de más bajos recursos: indios, mestizos, montubios y campesinos, quienes han encontrado en la medicina tradicional una alternativa menos costosa y más coherente con su cosmovisión", Plutarco Naranjo, Ruperto Escaleras, La medicina tradicional en el Ecuador: memorias de las Primeras Jornadas Ecuatorianas de Etnomedicina Andina, Universidad Andina Simón Bolívar / Corporación Editora Nacional. Quito - Ecuador, 1995.

${ }^{21}$ Confederación de Nacionalidades Indígenas de la Amazonía Ecuatoriana, (CONFENAIE). Entrevista, Andrés Tapia, responsable de comunicación (julio, 2020).
} 
bioseguridad, uso de medicina tradicional, cuidados, alimentación y dotación de kits de emergencia, así como protocolos desarrollados por las organizaciones. ${ }^{22}$

Las dirigencias, han mantenido espacios de coordinación digital permanente lo que ha permitido una comunicación directa desde el nivel organizativo nacional, por región, nacionalidades indígenas y liderazgos comunitarios. Con dificultades, sobre todo para llegar a territorios alejados, la traducción a 10 lenguas indígenas y el desarrollo propio e independiente del Estado de herramientas didácticas, resultó en un espacio colaborativo. ONGs, organizaciones indígenas y voluntarios implementaron estrategias para educar a la población sobre síntomas, cuidados y medidas de bioseguridad de la enfermedad. También la entrega de suministros significó desafíos por las medidas de confinamiento, restricción de circulación y estrictos horarios de toque de queda. En un primer momento de $2 \mathrm{pm}$ a $5 \mathrm{am}$, a partir del tercer mes de $7 \mathrm{pm}$ a $5 \mathrm{am}$. Las restricciones fueron liberadas en octubre de 2020, aunque se mantiene la restricción de circulación vehicular sin presentar alternativas para la población que no tiene vehículos particulares y debe usar el transporte público con alta exposición a contagios.

De otro lado, mediante comunicados oficiales y ruedas de prensa, las dirigencias indígenas, así como las organizaciones de derechos humanos y ambientalistas aliadas, han buscado generar opinión pública y un medio de presión continuo frente a las autoridades nacionales, los comités de operaciones de emergencia (COE) nacional y provinciales, así como la movilización de ayuda humanitaria para sus territorios.

Otro eje fundamental ha sido la organización en territorio para la entrega de alimentos a las comunidades mayormente aisladas, familias afectadas por la

22 Confederación de Nacionalidades Indígenas del Ecuador, CONAIE COMUNICADO ante la grave situación de los indígenas del Ecuador por el COVID-19. (Junio, 2020). Disponible en: https://conaie.org/2020/06/18/covid19/ (fecha de consulta: 26 de septiembre de 2020) 
consecuente crisis económica y atención con medicina tradicional indígena. Un tercer frente ha sido la vigilancia de vulneración de derechos y exigibilidad de un protocolo de emergencia intercultural en coherencia con el reconocimiento del país como un Estado Plurinacional. Un último y fundamental eje ha sido la asociación con diferentes organizaciones de la sociedad civil, fundaciones y otros aliados para la recaudación de fondos e insumos médicos. ${ }^{23}$

Se levantó además un fondo Panamazónico desde la COICA de 3 millones de dólares para apoyar a los pueblos indígenas de la Cuenca Amazónica a enfrentar la pandemia ya que consideran que los Estados de la región no han brindado la asistencia necesaria. ${ }^{24}$

En el mes de julio se llevó a cabo la Asamblea Mundial por la Amazonía, en el marco de la Campaña Mundial frente a impactos COVID-19 en pueblos indígenas, afrodescendientes y amazónicos. Entre otras, las demandas presentadas a los gobiernos de la región amazónica incluyen el fortalecimiento de la organización comunitaria para su autocuidado; moratoria de las actividades extractivas, garantía alimentaria y social; reorientar políticas neoliberales sobre la COVID 19 para reducir vulnerabilidades (Foro Social Panamazónico, Julio 2020)

\section{COVID-19 Y SISTEMAS DE SALUD "PROPIOS”}

\footnotetext{
23 Mediante este mecanismo han llegado brigadas médicas solidarias para la realización de pruebas COVID-19 y atención de salud emergente con el apoyo de las universidades privadas San Francisco de Quito (USFQ) y de las Américas (UDLA).

${ }^{24}$ El Fondo de Emergencia para la Amazonía es una cooperativa de donantes que trabaja en estrecha colaboración con las organizaciones indígenas. Rainforest Foundation U.S. hace de patrocinador bajo coordinación con el Consejo de Gobierno y representantes de las más de 10 organizaciones no gubernamentales que forman parte de la iniciativa, además de donantes y asesores. Las áreas de cobertura del fondo son: prevención y atención urgente e inmediata; provisión de alimentos y medicamentos; comunicaciones de emergencia y evacuaciones; protección y seguridad para los guardianes del bosque: y soberanía alimentaria y resiliencia comunitaria. Coordinadora de las Organizaciones Indígenas de la Cuenca Amazónica (COICA, 2020), "Fondo de Emergencia para la Amazonía". Disponible en: https://amazonemergencyfund.org/english/ [Fecha de consulta: 11 de septiembre de 2020]
} 
Una de las estrategias empleadas por la nacionalidad Waorani para discernir las "noticias falsas" y mantener a la población informada, fue levantar una memoria de las epidemias recientes, así buscaron darle un sentido a lo que sucede y organizarse mejor. Tomaron como referencia la epidemia de la polio en los años 60 , década que coincide con su contacto con la sociedad occidental. Los ancianos y ancianas tomaron la decisión de internarse en la selva para buscar sus propios alimentos y huir del virus. Aseguran que esta temporada es favorable porque es tiempo de frutos y monos gordos; sin embargo, esta es una solución temporal ya que al cambiar de estación climática, las condiciones serán otras. $^{25}$

En general, las autoridades indígenas de la Amazonía han realizado un llamado a su población a mantenerse lejos de los centros urbanos, que se lleve un control de entradas y salidas de las comunidades, se mantenga una comunicación activa desde cada familia y recurran a la medicina tradicional, sobre todo al consumo de plantas que aumentan la energía vital. La dirigencia afirma que pese a estos esfuerzos y un contingente movilizado en medio de dificultades económicas y sin respuestas efectivas del Estado, no se ha podido evitar que la pandemia se haya convertido en una amenaza de extinción para al menos algunas de las nacionalidades indígenas, sobre todo la Waorani y los pueblos en aislamiento voluntario. ${ }^{26}$

Tenemos mucha preocupación por esta epidemia, nosotros Waorani no tenemos defensas, somos pueblo de reciente contacto. Sabemos lo que pasó a nuestros abuelos con la epidemia de polio, no queremos que esto vuelva a pasar. Hemos activado un plan de prevención y preparación de la contingencia con una guía para las comunidades Waorani ${ }^{27}$

\footnotetext{
25 Confederación de Nacionalidades Indígenas de la Amazonía Ecuatoriana (CONFENAIE). Entrevista a Andrés Tapia, responsable de comunicación (julio, 2020).

${ }^{26}$ Ibídem.

${ }^{27}$ Nemonte Nenquimo. Una carta desde la Amazonía: uno destruye lo que no entiende. La líder ambiental del pueblo waorani lanza un aviso a los presidentes de los nueve países amazónicos. Artículo publicado en el diario El País, 12 de Octubre de 2020. Madrid.
} 
En la Amazonía se utilizan tanto la medicina ancestral como la medicina denominada "occidental" en referencia a las prácticas de la salud basadas en el uso de productos farmacéuticos procesados. Entre los productos naturales que diferentes comunidades amazónicas utilizan para enfrentar la pandemia constan la verbena, el ajo de monte, aguas de jengibre y limón, extractos de árbol de bálsamo, cáscara de sangre de drago y la hoja de menta. Las plantas de uso tradicional para la COVID-19 son utilizadas no únicamente como autoafirmación colectiva sino también como respuesta a la falta de otro tipo de medicinas. De todo esto se infiere que la estructura del sistema público de salud en la Amazonía ecuatoriana no cuenta con los recursos o estrategias necesarias para responder desde un enfoque intercultural a las necesidades de una población dispersa en amplias extensiones y con prácticas culturales propias sobre la salud y la organización comunitaria. ${ }^{28}$ En efecto, en su inmensa mayoría, las comunidades indígenas no han rechazado sin más el acceso a la medicina occidental, sino que han concebido y exigido la garantía del derecho a la salud desde una perspectiva intercultural y comunitaria,

Nemonte Nenquimo, lideresa waorani reconocida por la revista Times como una de las 100 personas más influyentes en el mundo por la lucha en defensa de los territorios y derechos de su pueblo, ${ }^{29}$ en julio del presente año manifestó que las comunidades han tenido que enfrentar la pandemia solas. Usando vaporizaciones e infusiones de plantas medicinales de la selva, enfrentaron la enfermedad. Afirmó entonces, que la ausencia del Estado les llevó a utilizar saberes ancestrales pese a que no hay evidencia de su efectividad para la COVID-19. Uno de los problemas más importantes es el del acceso a personal de salud por las distancias de los territorios indígenas a centros poblados, la comunicación en lenguas ancestrales y la falta de respuesta oportuna sobre los

28 Confederación de Nacionalidades Indígenas de la Amazonía Ecuatoriana (CONFENAIE). Entrevista a Andrés Tapia, responsable de comunicación (julio, 2020).

29 Times. The 100 most influential people of 2020. Nemonte Menquimo (Septiembre, 2020). https://time.com/collection/100-most-influential-people-2020/5888337/nemonte-nenquimo/ (fecha de consulta, 27 de septiembre de 2020). 
resultados de las pruebas. "Para las nacionalidades, no hay Estado (...) Los indígenas han tenido que buscar soluciones solos" es la forma en la que se refieren al tema los dirigentes. ${ }^{30}$

El Relator Especial de las Naciones Unidas sobre los Derechos de los Pueblos Indígenas, Francisco Cali al respecto menciona:

Basándome en la información urgente que ya he recibido de los Pueblos Indígenas de todas las regiones, puedo confirmar que la pandemia de COVID19 , tanto en sus impactos como en las respuestas emprendidas por algunos Estados, tiene un impacto directo en todos estos derechos y preocupaciones, y debe ser abordada de la manera más urgente por mi mandato. Espero con interés escuchar a otros Pueblos Indígenas, así como a los Estados y otros actores pertinentes sobre esta urgente situación, aunque gran parte de la información que estoy recibiendo es desgarradora y me crea profundas preocupaciones. ${ }^{31}$

Luego de la sentencia emitida por el tribunal de justicia de la provincia de Pichincha en respuesta a la demanda para "adoptar medidas urgentes para contener la COVID-19" en territorios de las nacionalidades indígenas, en especial de contacto inicial y en aislamiento voluntario como es el caso de Waorani y Tagaeri- Taromenane 32 ; el Ministerio de Salud Pública (MSP)

30 Antonio Vargas, dirigente del consejo de coordinación de la nacionalidad kichwa, en Mongabay. Covid-19 en Ecuador: indígenas enfrentan el riesgo de la automedicación. (Julio, 2020) Disponible en (fecha de consulta: 1 de octubre de 2020): https://es.mongabay.com/2020/07/covid-19-ecuador-indigenas-automedicacion/

${ }^{31}$ Fondo para el desarrollo de los pueblos indígenas de América Latina y el Caribe, FILAC. El Relator Especial de las Naciones Unidas sobre los Derechos de los Pueblos Indígenas pide que se haga aportaciones sobre los efectos del COVID-19 en los derechos de los Pueblos Indígenas. (mayo, 2020) Disponible en (fecha de consulta, 1 de octubre de 2020): https://www.filac.org/wp/comunicacion/filac-informa/el-relator-especial-de-las-naciones-unidassobre-los-derechos-de-los-pueblos-indigenas-pide-que-se-haga-aportaciones-sobre-los-efectosdel-covid-19-en-los-derechos-de-los-pueblos-indigenas-2/

32 Mongabay Latam, "Tribunal obliga al gobierno de Ecuador a proteger a la población indígena waorani durante la pandemia" (julio, 2020). Disponible en https://es.mongabay.com/2020/07/ecuador-tribunal-obliga-al-gobierno-a-proteger-a-la-poblacionindigena-waorani-covid-19/ (fecha de consulta, 19 de septiembre de 2020). 
coordina desde el mes de agosto con la dirigencia de la NAWE la visita de brigadas médicas. En un comunicado oficial, la entidad informa que se ha dotado de oxímetros y termómetros infrarrojos a los centros de salud en territorio Waorani en las provincias de Napo, Orellana y Pastaza. De todas formas, la debilidad de la atención pública se refleja en la necesidad de implementar actuaciones multipartes como la que el MSP ha establecido con las Universidades Católica del Ecuador (PUCE) y San Francisco (USFQ), y con la empresa petrolera Repsol que, precisamente es expresión de una de las principales amenazas a los territorios amazónicos. Hasta septiembre se realizaron 7.539 muestras para la detección de la COVID-19 en las comunidades Kichwa, Shuar, Waorani, Zapara, Achuar, Siona, Cofan, Secoya, Shiwiar y Andoa, con el objetivo de brindar atención inmediata y establecer cuarentenas preventivas en las que se encuentran 87 comunidades. ${ }^{33}$

Debe indicarse que desde el mes de julio, Ecuador forma parte del Plan de Promoción de la Salud y Comunicación de Riesgo para responder a la pandemia del COVID-19 en pueblos y nacionalidades indígenas liderado por la $\mathrm{OMS}^{34}$, que incluye el enfoque intercultural en materiales comunicacionales y educativos para la difusión integral (MSP, Septiembre 2020). En los meses de agosto y septiembre la comunicación sobre casos confirmados, decesos y personas que han superado la enfermedad son coordinados por los equipos de comunicación

\footnotetext{
${ }^{33}$ Ministerio de Salud Pública de Ecuador. MSP fortalece atención de primer nivel a Pueblos y Nacionalidades Indígenas (septiembre 2020). Disponible en https://www.salud.gob.ec/mspfortalece-atencion-de-primer-nivel-a-pueblos-y-nacionalidades-indigenas/ (fecha de consulta, 29 de septiembre de 2020).

34 "El Ministerio de Salud Pública - MSP, la Secretaría de Comunicación de la Presidencia SECOM, la Secretaría de Derechos Humanos, la Coordinadora de Radios Populares - CORAPE, el Grupo Parlamentario por los Derechos de los Pueblos y Nacionalidades, OPS/OMS, UNESCO, en conjunto con líderes y lideresas de las distintas organizaciones de los pueblos y nacionalidades del Ecuador (CONAIE, FENOCIN, Coordinadora Nacional del Pueblo Montubio del Ecuador, entre otros), definieron y actualmente ejecutan el "Plan de promoción de la salud y comunicación de riesgo para responder a la pandemia del Covid-19 en pueblos y nacionalidades del Ecuador". Disponible en: Acciones del Gobierno del Ecuador a favor de los pueblos y nacionalidades indígenas para afrontar la pandemia de COVID 19 (Julio, 2020) https://embassyecuador.ca/acciones-del-gobierno-del-ecuador-a-favor-de-los-pueblos-ynacionalidades-indigenas-para-afrontar-la-pandemia-de-covid-19/ (fecha de consulta, 27 de septiembre de 2020).
} 
del MSP y las dirigencias indígenas, respetando las estrategias empleadas por estas últimas a lo largo de la pandemia.

El Plan desarrollado por la OMS/OPS para brindar apoyo al Ministerio de Salud en el cumplimiento de las medidas cautelares emitidas en junio por la Corte Provincial de Pichincha, "promueve prácticas culturalmente adecuadas" acogiendo las demandas de las organizaciones indígenas para que las acciones en marco de la pandemia sean apropiadas cultural y territorialmente. Con la colaboración de la UNESCO "se realizó la adaptación e impresión de materiales de comunicación de riesgo con pertinencia cultural" y la entrega "de kits de higiene personal a 1000 personas de la provincia de Morona Santiago, 500 kits a personas de nacionalidad shuar y 500 kits a personas de nacionalidad achuar". ${ }^{35}$

Estas acciones se dieron en el marco del convenio tripartito entre OPS/OMS y la organización internacional PACHAMAMA y el apoyo del Ministerio de Salud Pública ${ }^{36}$ Esta respuesta conjunta ha ratificado los ejes de trabajo priorizados por las dirigencias: atención de emergencia, comunicación y alianzas estratégicas. Por otro lado se destaca que:

Según la Coordinadora de Organizaciones Indígenas de la Cuenca Amazónica COICA, Ecuador es el único país que cuenta con un trabajo conjunto entre la OPS/OMS y las distintas organizaciones gubernamentales y no gubernamentales con el fin de beneficiar a la población amazónica y apoyar la respuesta y prevención ante la COVID-19 en el Ecuador. (OMS, Agosto 2020).

En base al "protocolo de prevención y contención" construido por la CONAIE con apoyo de personas voluntarias y ONGs, se abrió la posibilidad de que los

35 Organización Mundial de la Salud. OPS/OMS apoya a las actividades de respuesta ante emergencia por COVID-19 en pueblos y nacionalidades del Ecuador (Agosto, 2020) https://www.paho.org/es/noticias/11-8-2020-opsoms-apoya-actividades-respuesta-anteemergencia-por-covid-19-pueblos (fecha de consulta, 11 de septiembre de 2020).

36 Organización Mundial de la Salud. OPS/OMS apoya a las actividades de respuesta ante emergencia por COVID-19 en pueblos y nacionalidades del Ecuador (Agosto, 2020) https://www.paho.org/es/noticias/11-8-2020-opsoms-apoya-actividades-respuesta-anteemergencia-por-covid-19-pueblos (fecha de consulta, 17 de septiembre de 2020). 
territorios indígenas puedan accionar de acuerdo a sus particularidades, lo que ha significado que hasta el momento "el nivel de contagio en comunidades sea menor y que se haya estrechado las relaciones solidarias al interior de las mismas"37.

Entre los avances que mencionan las instituciones gubernamentales constan el "fortalecimiento de conocimientos y capacidades para la gestión de información y comunicación en torno a la COVID-19", capacitación a 150 periodistas y comunicadores comunitarios y coordinadores de atención primaria de salud. De manera conjunta se desarrolló una batería de mensajes respetando las necesidades culturales $^{38}$ para enfrentar la tercera fase de la pandemia ${ }^{39}$. A pesar de presentarse una mejora en la coordinación, las dirigencias indígenas sostienen que el ejercicio al derecho a la salud de acuerdo a sus culturas y tradiciones, así como el derecho a vivir en un ambiente sano y seguro, son asuntos pendientes. Frente a un deterioro en las economías familiares, las comunidades ven agravadas su ya limitadas condiciones de vida, por lo que la CONAIE afirma que "el Gobierno no parece dar solución ni contingencia a comunidades que por años han sufrido falta de servicios y derechos básicos" 40 .

37 Apawki Castro, dirigente de la CONAIE. Confederación de Nacionalidades Indígenas del Ecuador, CONAIE COMUNICADO ante la grave situación de los indígenas del Ecuador por el COVID-19 (Junio, 2020). Disponible en: https://conaie.org/2020/06/18/covid19/ (fecha de consulta, 19 de septiembre de 2020).

${ }^{38}$ De acuerdo a la persona responsable de comunicación de la CONFENAIE, Andrés Tapia, a partir de la estrategia comunicacional desarrollada por las organizaciones indígenas, el Ministerio de Salud y otras entidades han replicado los mensajes en lenguas indígenas, así como la formación a comunicadores comunitarios y personal de salud. Esto en apoyo de los medios comunitarios y CORAPE. Confederación de Nacionalidades Indígenas de la Amazonía Ecuatoriana, (CONFENAIE). Entrevista al responsable de comunicación, Andrés Tapia (julio, 2020).

39 Organización de las Naciones Unidas Ecuador. Pueblos y nacionalidades en el centro: la estrategia nacional para promocionar la salud en tiempos de pandemia (Mayo, 2020). Disponible en $\quad$ https://ecuador.un.org/es/45880-pueblos-y-nacionalidades-en-el-centro-la-estrategianacional-para-promocionar-la-salud-en [Fecha de consulta, 19 de septiembre de 2020]

${ }^{40}$ Prensa latina, "Denuncian insuficiente atención de salud en zonas rurales de Ecuador" (28 de septiembre, 2020). Disponible en (fecha de consulta, 29 de septiembre de 2020): https://www.prensalatina.cu/index.php/component/content/?o=rn\&id=399713\&SEO=denuncianinsuficiente-atencion-de-salud-en-zonas-rurales-de-ecuador 
Durante décadas, grandes empresas y gobiernos nos han ofrecido lo que llaman "desarrollo económico" a cambio de la extracción de recursos naturales irremplazables. En la realidad, aquellas prácticas sin control nos han esclavizado y han contaminado nuestros territorios, cuyo hábitat es de vital importancia no solo para los pueblos que en ella convivimos, sino para todo el planeta" (Nadino Calapucha, COICA $)^{41}$.

Las actividades extractivas y otras ilícitas no han parado y amenazan la sobrevivencia de los pueblos indígenas ${ }^{42}$, al igual que el impacto desproporcionado de la crisis económica en las oportunidades para su desarrollo ${ }^{43}$. Además, Nadino Calapucha de la COICA advierte que de no tomar acciones inmediatas para implementar medidas de salud culturalmente adecuadas con planes y presupuestos para pueblos indígenas, "seremos testigos de un etnocidio" 44 .

41 Nadino Calapucha, COICA. "Pueblos Indígenas de Amazonía y Covid-19: No nos hemos quedado esperando ayuda que sabemos nunca llegará", Amnistía Internacional (agosto 2020). Disponible en (fecha de consulta, 11 de octubre de 2020): https://www.amnesty.org/es/latest/news/2020/08/pueblos-indigenas-amazonia-covid19/

42 "Varios factores se conjugan en los contagios en la Amazonía. A pesar del estado de excepción decretado por el gobierno nacional, las actividades extractivas realizadas por empresas petroleras y mineras continuaron en los territorios amazónicos; y en varias zonas, como el Yasuní, inclusive se intensificaron. Muchas empresas no necesariamente han aplicado protocolos de prevención de contagio del COVID-19, principalmente las subcontratistas (servicios de comida, limpieza, entre otras), con trabajadores foráneos que rotan por turnos para el ingreso a campos petroleros y mineros, circulando por las comunidades. Hay actividades de extracción forestal principalmente de balsa, que se efectúa en territorios kichwa y waorani que también inciden en los contagios. Las empresas madereras que operan en la región amazónica tienen su sede en la ciudad de Guayaquil, y las personas que se dedican al comercio de la balsa provienen de esa ciudad. Ingresan a los territorios y compran madera a miembros de las comunidades, una cuestión que ocurre durante todo el año, se intensifica en ciertos períodos y que no se suspendió durante la denominada restricción a la movilidad entre provincias. Estas actividades extractivas legales e ilegales suponen movilidad de personas externas hacia los territorios indígenas. En el caso waorani, personas dedicadas a la tala de balsa ingresaron a aquellas comunidades que cuentan con carreteras como la vía Auca, donde están las comunidades de Tiguino y Bataboro, provincia de Orellana y Pastaza". Ivette Vallejo, Katty Álvarez, "La pandemia del Coronavirus en la Amazonía ecuatoriana: vulnerabilidades y olvido del Estado", en Cuadernos de Campo (São Paulo, online), vol. 29, núm. 1, 2020, pp. 95110.

${ }^{43}$ Confederación de Nacionalidades Indígenas de la Amazonía Ecuatoriana (CONFENAIE). Entrevista a Andrés Tapia, responsable de comunicación (Septiembre, 2020).

44 Nadino Calapucha, COICA. "Pueblos Indígenas de Amazonía y Covid-19: No nos hemos quedado esperando ayuda que sabemos nunca llegará". Amnistía Internacional (agosto 2020). 


\section{V.SOBERANÍA INDÍGENA FRENTE A DEPENDENCIAS MÚLTIPLES Y ESTRUCTURALES}

\section{Derechos colectivos y 'brecha de la implementación'}

De acuerdo con la Declaración de los Pueblos Indígenas aprobada por Naciones Unidas (2007) y el Convenio 169 de la Organización Internacional del Trabajo OIT (1989), los Estados deben garantizar los derechos colectivos de los pueblos indígenas, los derechos culturales y la identidad, la autodeterminación y los derechos a la salud, la educación y el empleo, entre otros. Estos instrumentos enfatizan el derecho de los pueblos indígenas de preservar y fortalecer sus propias instituciones, culturas y tradiciones, además de trabajar por su desarrollo de acuerdo a sus aspiraciones y necesidades.

En el Ecuador, los 14 pueblos y 18 nacionalidades indígenas, el pueblo afrodescendiente y el pueblo montubio son reconocidos a nivel constitucional y conforman el conjunto de pueblos que, juntamente con la sociedad occidental o mayoritaria, conforman el Estado Plurinacional (art. 1).

Efectivamente, la Constitución del Ecuador incorpora el principio de la plurinacionalidad como parte de la definición de la forma del Estado. La plurinacionalidad sería el concepto utilizado para superar la referencia a la pluriculturalidad, término común en los textos constitucionales latinoamericanos reformados a lo largo de los años noventa. Con ello, se pretende asentar la dimensión prescriptiva del reconocimiento de la existencia de distintas culturas o grupos culturales. Frente a la comprensión descriptiva de la existencia de distintas culturas, propia del constitucionalismo multicultural, la plurinacionalidad empujaría a transformaciones de las estructuras institucionales y jurídicas del Estado. ${ }^{45}$

Disponible en (fecha de consulta, 11 de octubre de 2020): https://www.amnesty.org/es/latest/news/2020/08/pueblos-indigenas-amazonia-covid19/

45 Marco Aparicio Wilhemi, "Estado, organización territorial y constitucionalismo plurinacional en Ecuador y Bolivia. ¿Una década ganada?”, en Revista d'estudis autonòmics i federals, núm. 27, 2018, p. 121 (pp. 118-146). 
Ahora bien, el avance constitucional ha implicado hasta el momento transformaciones limitadas debido a la existencia de importantes brechas de implementación ${ }^{46}$. Estas brechas son compartidas en el conjunto de América Latina, y así ha sido recogido por un reciente informe de la CEPAL que señala las principales carencias en: 47

a. Derechos consagrados a nivel internacional: Derecho de propiedad colectiva, el control, acceso y uso de los recursos naturales, el derecho a un consentimiento libre, previo e informado.

b. Reconocimiento constitucional: Concreción de los mecanismos de demarcación, titulación y saneamiento territorial. Se podría añadir, igualmente, la falta de voluntad política para el desarrollo de las autonomías indígenas. ${ }^{48}$

c. Leyes y políticas de tierras indígenas: Burocratización y lentitud de procesos de titulación, reducción de las tierras ancestrales, procesos de saneamiento inconclusos.

A estos factores se suman los procesos de criminalización frente a las demandas territoriales de los pueblos indígenas que tratan de enfrentarse a las leyes y políticas que favorecen el extractivismo y el neoextracitvismo en sus territorios, y leyes y políticas de conservación que excluyen a los pueblos indígenas (CEPAL, 2020).

En marzo del presente año varias organizaciones que hacen parte de la Alianza por los Derechos Humanos de Ecuador anunciaron una "Acción urgente para proteger a los pueblos indígenas de COVID-19 en Ecuador" para demandar al gobierno nacional las "garantías sanitarias urgentes, idóneas y culturalmente pertinentes frente a la emergencia sanitaria y el cumplimiento de los derechos a

\footnotetext{
46 Terminología que hizo célebre quien fuera Relator Especial de Naciones Unidas sobre los derechos de los pueblos indígenas, el académico mexicano Rodolfo Stavenhagen.

47 Comisión Económica para América Latina y El Caribe, CEPAL, Los pueblos indígenas de América Latina -Abya Yala y la Agenda 2030 para el Desarrollo Sostenible (2020). Disponible en https://www.cepal.org/es/publicaciones/45664-pueblos-indigenas-america-latina-abya-yala-laagenda-2030-desarrollo-sostenible [Fecha de consulta, 14 de octubre de 2020]

${ }^{48}$ Aparicio Wilhemi, "Estado, organización territorial...", cit., p. 121.
} 
la vida, integridad, acceso a la salud y autodeterminación de los Pueblos y Nacionalidades Indígenas, así como de las comunidades campesinas". Mediante una carta pública, expresaron su preocupación debido a la:

Especial vulnerabilidad (...) debido a la persistencia de condiciones de desigualdad, exclusión y discriminación en el acceso general a los bienes y servicios de la sociedad, así como por las condiciones de relativo aislamiento geográfico de sus territorios -sobre todo en el caso de las poblaciones indígenas amazónicas y de la costa. ${ }^{49}$.

Las vulnerabilidades preexistentes, un sistema jurídico y político que favorece la explotación de materias primas en territorios indígenas, y actividades que no fueron detenidas durante la pandemia, presentan un escenario perjudicial para enfrentar los efectos de la pandemia. Por otro lado, durante el confinamiento se evidencia una tendencia en los gobiernos a priorizar proyectos de inversión para la producción minera, hidrocarburífera, bienes y servicios forestales, tráfico de especies, entre otros. La criminalización de la protesta social indígena en defensa de sus derechos y sus territorios, contribuye a una mayor fragilidad en este contexto. ${ }^{50}$

La pandemia parece haber exacerbado los factores de estrés en el territorio y aumentado exponencialmente las condiciones de desigualdad para el acceso a servicios básicos de alimentación, salud, agua y saneamiento. La educación en especial para niños en formación primaria, ha sido una muestra de un sistema que no integra las dimensiones culturales y territoriales. La educación en línea en territorios alejados que no disponen de internet por núcleo familiar, o

\footnotetext{
${ }^{49}$ Amazon Frontlines (marzo, 2020). Acción urgente para proteger a los pueblos indígenas de COVID-19 en Ecuador. Disponible en (fecha de consulta, 17 de septiembre de 2020): https://www.amazonfrontlines.org/chronicles/accion-urgente-para-proteger-a-los-pueblosindigenas-de-covid-19-en-ecuador/

50 CEPAL. Comisión Económica para América Latina y El Caribe, Los pueblos indígenas de América Latina -Abya Yala y la Agenda 2030 para el Desarrollo Sostenible, (2020). Disponible en: https://repositorio.cepal.org/bitstream/handle/11362/45664/51/S2000125 es.pdf [Fecha de consulta, 22 de septiembre de 2020].
} 
dispositivos electrónicos para acceder a las jornadas educativas, demuestra el abandono en el que se encuentran niños y jóvenes indígenas.

Así, podemos afirmar que en el período marzo-septiembre de 2020, la pandemia detonó problemas estructurales de la organización territorial del Estado que a su vez visibilizó una institucionalidad lejana de la realidad de la población, es especial en la Amazonía.

En seis meses sucedieron varios eventos paralelos que demuestran cómo diferentes factores de estrés determinan condiciones de vulnerabilidad en los ecosistemas y en las comunidades. Dos inundaciones que dejaron sumidas bajo el agua a las comunidades Kichwa de Sarayaku y Parkayaku, en la provincia de Pastaza $^{51}$. La atención de emergencia, medidas de bioseguridad, dotación de víveres y vituallas, así como las labores de reconstrucción se llevaron a cabo de manera auto gestionada por la organización indígena.

Tres días después de la inundación, vino la Secretaría de Gestión de Riesgos a entregar unos colchones. Las familias estábamos restableciendo nuestras vidas, haciendo unos ranchitos para poder dormir, pero desde que dejaron los colchones, no hemos tenido más visitas de ninguna autoridad, concluye el presidente ${ }^{52}$

\footnotetext{
51 Sarayaku, es una comunidad kichwa de la Amazonía ubicada a las orillas del río Bobonaza, en la provincia de Pastaza. La comunidad está compuesta por 380 familias y 1380 habitantes, de acuerdo al último censo interno. Durante el período de marzo-junio de 2020 se dieron inundaciones por la crecida de los ríos Bobonaza, Sarakilly y Rotuno. En la primera inundación se perdieron 33 casas, criaderos avícolas, piscinas de cachama, bocachico y tábano. También se perdieron escuelas, aulas, archivos, salas de visitas, de conferencias, de tamboreo, de baile, que son parte de su cultura. Chakras de plataneras, yucales, maizales, quedaron bajo el agua. Los caminos intercomunitarios y siete puentes peatonales también se perdieron."Río Bobonaza se lleva 30 casas de Sarayaku y el coronavirus llega a sus dominios", en El Universo (marzo, 2020). Disponible en (fecha de consulta, 1 de octubre de 2020): https://www.eluniverso.com/noticias/2020/06/14/nota/7872525/rio-bobonaza-se-lleva-30-casassarayaku-coronavirus-llega-sus

52 Raúl Túpac Amaru Viteri Gualinga, "Río Bobonaza se lleva 30 casas de Sarayaku y el coronavirus llega a sus dominios" (marzo, 2020), en El Universo, Disponible en: https://www.eluniverso.com/noticias/2020/06/14/nota/7872525/rio-bobonaza-se-lleva-30-casassarayaku-coronavirus-llega-sus (fecha de consulta, 1 de octubre de 2020).
} 
Estos acontecimientos plantean el debate urgente sobre los efectos del cambio climático en la región. Al mismo tiempo que se observa una débil respuesta estatal para dotar de insumos de emergencia para cubrir necesidades básicas de alimentación, salud, seguridad y hábitat, se destaca la gestión de recursos por medios propios. En las dos ocasiones, la dotación de kits de comida, vituallas y recursos para la reconstrucción fueron provistos por la cooperación, ante la ausencia institucional.

El 7 de abril se dio el derrame de petróleo del Sistema de Oleoductos Trans Ecuatorianos (SOTE) y el Oleoducto de Crudos Pesados (OCP). La empresa responsable informó que la rotura de la tubería se debió a la erosión en el cauce del río Coca. Pese a que el gobierno no ha confirmado la cantidad de petróleo que cayó en el río, se estima que serían alrededor de 8900 barriles. Los expertos aducen que este evento era previsible por las condiciones de la zona proclives a deslizamientos de tierra, erupciones volcánicas y terremotos. Varias alertas se dieron al momento de la construcción, mismas que no fueron tomadas en cuenta ${ }^{53}$. Estos acontecimientos demuestran el riesgo de construir en zonas de alto riesgo geológico, alta sensibilidad social y ecológica. De todo esto, se encuentran afectadas comunidades indígenas kichwa que viven aguas abajo. ${ }^{54}$

En territorio Achuar en los últimos 6 meses se han cortado 20000 árboles de balsa en la zona ubicada en las riberas del río Copataza. "La pandemia lo que ha hecho es exacerbar la tala" (Fundación Alejandro Labaka en Mongabay, Septiembre 2020). La tala ilegal de madera en medio de la emergencia sanitaria denota la falta de control de la autoridad ambiental y la fragilidad del territorio. Además de crear condiciones propicias para la propagación del coronavirus en

\footnotetext{
53 La construcción del OCP inició en el año 2001 con expectativas de percibir ganancias alrededor de 440 millones de dólares y 11000 nuevos empleos. Mongabay Latam, "Ecuador: la rotura del oleoducto OCP revela el impacto de construir en zonas de alto riesgo" (mayo 2020). Disponible en: https://es.mongabay.com/2020/05/ecuador-rotura-oleoducto-ocp-petroleo/ (fecha de consulta, 26 de septiembre de 2020).

${ }^{54}$ Ibidem.
} 
territorios indígenas y poner en especial riesgo a los Pueblos Indígenas en Aislamiento Voluntario (PIAVs). ${ }^{55}$

La CONAIE ha emitido comunicaciones informando sobre la "grave situación de los indígenas del Ecuador". Entre las demandas que le plantea al gobierno nacional es que se "detengan inmediatamente todas las actividades extractivas legales e ilegales (...) ya que constituyen focos de contagio que aumentan exponencialmente los riesgos" para las comunidades. ${ }^{56}$

La nacionalidad Waorani presentó una demanda el 20 de mayo exigiendo medidas cautelares para garantizar los derechos a la salud, la vida y la autodeterminación. Con una creciente propagación de los contagios por COVID19 en las comunidades de la selva amazónica, la población Waorani recibió un dictamen favorable emitido por el tribunal provincial de Pichincha mediante el cual obliga al Ministerio de Salud y al Ministerio de Inclusión Social una comunicación y coordinación directa con los líderes Waorani para asegurar el suministro de pruebas, dotación de alimentos y otras necesidades. Al Ministerio de Ambiente y Agua, el tribunal le ordenó que realice un informe a detalle sobre el monitoreo a la minería ilegal, la tala y actividades relacionadas con el tráfico de drogas en la zona. El dictamen tardó 27 días, tiempo en el cual en las 11 comunidades con presuntos casos a finales de mayo se confirmaron 190 casos, dos fallecidos y otros hospitalizados en condiciones de gravedad hasta esa fecha.

Las medidas cautelares fueron acogidas parcialmente, dejando sin atender la petición de la suspensión inmediata de todas las actividades extractivas en

\footnotetext{
55 Mongabay Latam. "Alerta en la Amazonía ecuatoriana: madereros ilegales arrasan en medio de la pandemia" (Septiembre 2020). Disponible en : https://es.mongabay.com/2020/09/tala-ilegalen-ecuador-amazonia-pueblos-indigenas/ (fecha de consulta: 26 de septiembre de 2020) [Fecha de consulta, 11 de octubre de 2020]

${ }^{56}$ Confederación de Nacionalidades Indígenas del Ecuador, CONAIE. COMUNICADO ante la grave situación de los indígenas del Ecuador por el COVID-19 (junio, 2020). Disponible en: https://conaie.org/2020/06/18/covid19/ (fecha de consulta, 10 de septiembre de 2020).
} 
territorio Waorani, actividades consideradas por los demandantes como "vectores de contagio" ya que éstos se han dado principalmente en comunidades aledañas a lugares donde se dan operaciones petroleras, explotación forestal y minería ilegal que no se han detenido durante la cuarentena. El 29 de junio, la magistrada amplió la sentencia a las provincias de Napo, Pastaza y Orellana, estableciendo la necesidad de una coordinación adecuada con las autoridades de la nacionalidad Waorani (NAWE, AMWE, CONCONAWEP), así como la disposición para que el Ministerio de Salud cubra los costos del traslado de pacientes y personal médico hacia las comunidades para quienes no pueden salir. Finalmente, la magistrada dictó que se deben suministrar dotaciones de alimentos cada 15 días hasta "la superación definitiva de la pandemia". Ante esto, las autoridades gubernamentales han presentado solicitudes de revocatoria el 29 de junio y 6 de julio, dejando en duda la voluntad política para garantizar los derechos de las comunidades indígenas y sus necesidades específicas durante la pandemia.

La solicitud de medidas cautelares realizada por la nacionalidad Waorani se basa en el riesgo sobre el derecho a la vida ya que se considera como un bien jurídico protegido, cuya vulneración recaería en una conducta punible a nivel penal. De acuerdo con la legislación ecuatoriana, si se comprueba un atentado a la vida debido al incumplimiento de las medidas necesarias para para asegurar la supervivencia de las comunidades Waorani que tienen un contacto de menos de 60 años con la civilización occidental y los pueblos en aislamiento voluntario Tagaeri-Taromenane, se podría configurar un crimen de etnocidio (art. 57 de la Constitución ecuatoriana). Así, las medidas cautelares además buscan la protección de los Pueblos en aislamiento voluntario Tagaeri, Taromenane, ya que el centro de mayor contagio en la nacionalidad Waorani se encuentra cerca de los senderos por donde transitan estos grupos humanos.

Este y otros trámites de exigibilidad y vigilancia de los derechos de los pueblos indígenas durante la pandemia se encuentran impulsados por la Alianza por los Derechos Humanos de Ecuador. Entre sus acciones destaca la presentación 
ante la Comisión Interamericana de Derechos Humanos (CIDH) de un informe sobre vulneraciones a derechos en el marco de la pandemia por la COVID-19 el día 13 de julio de 2020 en el que se hace énfasis en la situación de pueblos indígenas, comunidades afro, mujeres, niñas y niños, y personas privadas de libertad. La Alianza argumenta que la falta de respuesta estatal, sus inadecuadas, improvisadas e ineficaces acciones en el manejo de la emergencia sanitaria han generado una cadena de vulneraciones de derechos humanos que se evidencia en un trato alejado de mínimos estándares de dignidad. La Comisión Interamericana de Derechos Humanos (CIDH) expresó su "alarma" por la propagación de la pandemia entre pueblos indígenas amazónicos de Ecuador mediante un pronunciamiento el 30 de mayo de 2020. Este organismo alertó al Estado sobre la especial vulnerabilidad de los pueblos indígenas y recuerda la necesidad de extremar medidas que garanticen su derecho a la salud desde enfoques de interculturalidad, género y solidaridad intergeneracional, según la Res. 01/20 Pandemia. ${ }^{57}$

\section{Centralismo y homogeneidad estatal vs. multi-gobernanza desde realidades localmente situadas}

De acuerdo a la Constitución del Ecuador (2008), los riesgos se deben gestionar bajo el principio de descentralización subsidiaria, lo que significa que las instituciones del Estado tienen responsabilidad directa dentro de su ámbito geográfico. En caso de que sus capacidades sean insuficientes, aquellas instancias de mayor capacidad técnica, financiera y ámbito geográfico deben brindar apoyo para las respuesta necesarias sin relevarlos de su responsabilidad (Art. 390). En la Ley de Seguridad Pública y del Estado (2009) se establece que la ejecución de la gestión de riesgos es responsabilidad del sistema Descentralizado de Gestión de riesgos, que entre sus funciones consta la generación y democratización del acceso y la difusión de información, coordinación entre instituciones públicas y privada, la educación y difusión para

\footnotetext{
57 El informe se encuentra disponible en (fecha de consulta, 11 de septiembre de 2020): https://www.oas.org/es/cidh/decisiones/pdf/Resolucion-1-20-es.pdf
} 
fortalecer capacidades, y coordinar la cooperación de la ayuda humanitaria (Art. 3). Así mismo, se establece que los denominados Comités de Operaciones de Emergencia (COE), "son las instancias interinstitucionales responsables en su territorio de coordinar las acciones tendientes a la reducción de riesgos, y a la respuesta y recuperación en situaciones de emergencia y desastre" (Art 24, Reglamento a la Ley de Seguridad Pública y del Estado) ${ }^{58}$.

Pese a que el Ecuador se reconoce como un Estado Plurinacional en su Constitución (2008), en la gestión de riesgos la relación intercultural se limita a una mención respecto a los procesos de educación en los niveles básico, medio y técnico (Art. 25, Reglamento a la Ley de Seguridad Pública y del Estado) ${ }^{59}$. En la resolución inicial del COE para las respuestas frente a la pandemia, se consideran las restricciones de movilidad interna, ingresos y salidas del país, así como la atención de salud en emergencia. No se hace ninguna referencia a consideraciones territoriales, culturales o de género, por lo que se infiere que se las decisiones estatales a nivel nacional parten de la consideración de que la población es homogénea. De ahí la demanda de los pueblos indígenas por política interculturales (Servicio Nacional de Gestión de Riesgos y Emergencias, 14 de marzo de 2020) ${ }^{60}$.

La Amazonía es considerada como un "ecosistema necesario para el equilibrio ambiental del planeta y que se constituirá en una circunscripción territorial especial, con una planificación integral que incluirá aspectos sociales, económicos, ambientales y culturales, y cuyo ordenamiento territorial, además debe garantizar la conservación y protección de sus ecosistemas y el principio del sumak kawsay o buen vivir" (art. 250 de la Constitución). Pese a esta disposición, la selva amazónica es una zona en la que se han priorizado

\footnotetext{
${ }^{58}$ Reglamento a la Ley de Seguridad Pública y del Estado, 2010 (Última modificación, 14 de julio de 2017).

59 Ibídem.

${ }^{60}$ Servicio Nacional de Gestión de Riesgos y Emergencias. "Resoluciones COE Nacional 14 de marzo 2020". Diponsible en https://www.gestionderiesgos.gob.ec/resoluciones-coe-nacional14-de-marzo-2020/ [Fecha de consulta 2 de dicembre de 2020]
} 
actividades extractivas con consecuencias en el deterioro de la biodiversidad, la calidad de vida de las personas, conflictos socioambientales, problemas vinculados a la salud y el desarrollo autónomo de las comunidades y violencia contra mujeres y niñas.

Las principales actividades extractivas están relacionadas a la obtención de petróleo, madera y minería que tienen escaso control y regulación. Se destaca el incumplimiento de protocolos y medidas de prevención que devienen en derrames de crudo en ríos o contaminación, como es el caso del mercurio. A esto se suman las crisis tanto económica como política y social. El gobierno de Ecuador parece haber optado por políticas que "intensifican aún más la economía extractiva para tratar de recuperarse lo más rápidamente posible tras las pérdidas y las crisis"61. El deterioro de la calidad del empleo, el creciente desempleo y la escasez de alimentos está obligando a replantear a los pueblos originarios volver a la chacra para sembrar sus propios alimentos y a formas tradicionales de vida en zonas que sufren un deterioro importante de la biodiversidad; al mismo tiempo que deben defenderse de factores externos que ponen en riesgo su sobrevivencia debido a la actividades extractivas.

Nemonte Nenquimo, líder Waorani publicó una carta dirigida a los presidentes de los países amazónicos en la que afirma que los incendios siguen destruyendo la selva, el derrame de petróleo y otros minerales contaminan los ríos debido a las actividades extractivas en sus territorios, la tala de los bosques vírgenes para el ingreso de pastizales y ganado, así como agricultura extensiva, siguen siendo riesgos inminentes para la supervivencia de los pueblos indígenas. Afirma que las decisiones de los gobiernos buscan estimular una economía que nunca les ha beneficiado. Frente a este contexto, la lucha es por proteger sus formas de vida. En este comunicado sostiene que los "cowori" (palabra en Wao Tededo que significa "extraño, hombre blanco que sabe muy poco para el poder que

${ }^{61}$ Ma. Ángeles Fernández y Jairo Marcos, "La vida a lomos de la Amazonía menguante", en EsGlobal, 13 de octubre de 2020. Disponible en (última visita 20 de octubre de 2020): https://www.esglobal.org/la-vida-a-lomos-de-la-amazonia-menguante/ [última visita 20 de octubre de 2020] 
ejerce y el daño que causa) no comprenden el valor de la vida en la Amazonía porque no la conocen"62.

Cuanto menos sepas sobre algo, menos valor tiene para ti y es, por lo tanto, más fácil de destruir. Y por fácil, quiero decir: sin culpabilidad, sin remordimientos, sin sentirse estúpidos e, incluso, con todo derecho. $Y$ esto es exactamente lo que nos están haciendo a nosotros como pueblos indígenas, a nuestros territorios de selva tropical, y también al clima de nuestro planeta. ${ }^{63}$

La respuesta, considerada tardía por las organizaciones indígenas, da cuenta de una institucionalidad estatal que aplica políticas universales y homogéneas sin atender las necesidades específicas e impactos diferenciados de la población. Las condiciones de origen, pertenencia étnica, género, situación geográfica y factores de riesgos en comunidades con ecosistemas frágiles, además de las desigualdades propias de un sistema económico que ha ubicado a las comunidades indígenas y rurales en el último escalón social, son parte central del problema.

La tensión irresuelta entre lo nacional y lo local deja ver grietas en la coordinación durante la emergencia. En los dos primeros meses, el Comité de Operaciones de Emergencias COE nacional definió las respuestas del gobierno mediante un mecanismo centralizado y distante de las necesidades específicas, culturales y territoriales. En casos particulares, la coordinación entre los gobiernos locales y las organizaciones indígenas, permitieron una mejor y más eficaz respuesta. Sin embargo, en aquellas que no hubo coordinación, no solo que los casos de contagios son más significativos, sino que las dificultades para

\footnotetext{
${ }^{62}$ Nemonte Nenquimo, "Una carta desde la Amazonía: uno destruye lo que no entiende. La líder ambiental del pueblo Waorani lanza un aviso a los presidentes de los nueve países amazónicos", en el diario El País, 12 de octubre de 2020. Disponible en: https://elpais.com/opinion/2020-1012/una-carta-desde-la-amazonia-uno-destruye-lo-que-no-entiende.html [Última visita 20 de octubre de 2020]

63 Ibídem.
} 
el acceso a bienes de primera necesidad fue más complejo (Entrevista Belén Páez, Fundación Pachamama; Mayo-Junio, 2020)64.

A partir del dictamen favorable para la nacionalidad Waorani, las autoridades de salud iniciaron un proceso coordinado de prevención y seguimiento de la propagación de la COVID-19 en agosto de 2020. Sin embargo, para dirigentes indígenas y organizaciones de derechos humanos, la respuesta tardía es insuficiente. Quedan preguntas que contestar: ¿Cuáles son los puntos ciegos en la aplicación de los estándares de respuesta frente a una emergencia sanitaria? ¿Cuál es la relación entre el sistema universal de derechos humanos y una visión intercultural que permita una aplicación de los derechos colectivos de los pueblos indígenas en el marco de la pandemia? ¿De qué manera las respuestas a la crisis económica asociada al contexto actual pueden considerar medidas específicas que respondan la diversidad cultural y las vulnerabilidades que enfrentan los pueblos indígenas para alcanzar un desarrollo humano integral? ¿Es posible la construcción del Estado Plurinacional? ¿Pueden las políticas nacionales responder a las realidades situadas de las poblaciones indígenas? ¿Se pueden aplicar acciones descentralizadas y desconcentradas?

\section{CONCLUSIONES}

En términos generales, y de manera especial durante los primeros compases de la pandemia, las decisiones implementadas por parte del estado ecuatoriano frente al avance de la COVID-19 en territorios amazónicos constituyen respuestas estandarizadas frente a la pandemia que no sólo desconocen la pluralidad de la población, sino además las particularidades de los territorios, los usos y prácticas asociadas a los recursos de la biodiversidad, las vulnerabilidades y necesidades de cada comunidad, incluso de cada género. Ello demuestra que las políticas en tiempos de emergencias no son neutrales, no son respuestas de carácter meramente 'técnico' o 'sanitario' sino que contienen un alto grado de intencionalidad política. Esta narrativa que se reproduce desde el Estado se comprende en lo que Rivera Cusicanqui

${ }^{64}$ Entrevista, Belén Páez, Directora Fundación Pachamama (mayo-junio, 2020). 
denomina "racismo epistémico". La jerarquización de formas de pensamiento que se expresan y se materializan en las acciones públicas, refuerza unas prácticas de colonización sobre poblaciones indígenas y sus territorios.

Frente al centralismo institucional del Estado y de los poderes económicos, junto con la concepción hegemónica de la salud, las organizaciones indígenas proponen una respuesta desconcentrada y situada en los territorios. Con dificultades y limitados recursos, se observa cómo las dirigencias han impulsado mecanismos propios para responder a las necesidades de alimentación y bioseguridad en las comunidades; comunicación interna y en lenguas propias; articulación de un sistema cooperativo para recolección de donaciones, pruebas para la COVID-19, asistencia especializada e insumos médicos; y finalmente acciones legales de exigibilidad de derechos.

Desde los conocimientos situados, las comunidades indígenas han procurado en ejercicio de su autonomía una respuesta emergente, así como la demanda continua por los riesgos asociados a las actividades extractivas que no fueron suspendidas durante el confinamiento. En este escenario, los pueblos indígenas de la Amazonía se enfrentan a una crisis sanitaria acompañada de una crisis económica y política que deviene de un modelo económico neoliberal cada vez más depredador e incompatible con la vida

De igual manera, la gestión de la emergencia sanitaria no consideró los derechos de los pueblos indígenas para acceder a servicios de salud apropiados con sus culturas y tradiciones. La lejanía de muchas comunidades y condiciones previas de desigualdad ahondaron la vulnerabilidad de la población. Las mujeres que de por sí en zonas rurales y comunidades indígenas sufren altos índices de violencia machista, se ven limitadas en el acceso al sistema de justicia, a salud sexual y reproductiva, y han visto deterioradas sus economías, mayormente ubicadas en la informalidad. La migración inversa -otra consecuencia del modelo de desarrollo- también ha jugado un papel importante no sólo en el incremento de casos positivos de COVID-19, sino en la necesidad de formas de reorganización familiar y comunitaria. Ello va de la mano de la creación de redes 
de economía no monetaria, volviendo al intercambio y el trueque como formas alternativas para sostenerse en una crisis que tiene múltiples aristas.

El enfoque espacio-temporal priorizado por las organizaciones indígenas es del "cuidado comunitario", en el que se proponen respuestas acorde a sus culturas, capacidades organizativas y las realidades en los territorios en tiempos de pandemia. El Estado de su lado, y en el marco de una excepcionalidad que en realidad es regla, ha desconocido ampliamente la garantía de los derechos colectivos de los pueblos indígenas, como lo demuestra el hecho de que ninguna organización indígena fuera parte durante los momentos críticos de la pandemia de los Comités Operativos de Emergencia, pese a haber solicitado su inclusión. Salvo algunos casos en los que se logró coordinación con entidades locales, como es el caso de la Provincia de Pastaza y la ciudad del Puyo, la mayoría de las respuestas de los pueblos fueron autogestionadas.

Se destaca en la gestión de la emergencia en las comunidades, la restricción del acceso a los territorios mediante un control propio, la comunicación en lenguas propias, el abastecimiento de productos de primera necesidad, coordinación con otros actores, levantamiento de fondos, restricciones de reuniones y actividades turísticas, desarrollo de protocolos propios de prevención de la enfermedad, la revalorización de la medicina ancestral y la identificación de grupos vulnerables. En este último aspecto, se destacan los pueblos transfronterizos, los pueblos en contacto inicial y en aislamiento voluntario, las personas ancianas y con afectaciones de salud previas, las mujeres, niños y niñas.

Si bien el contagio no pudo ser detenido, se estima que el riesgo fue reducido frente a las amenazas y vulnerabilidades de los territorios indígenas amazónicos. Mantener a las comunidades informadas, abastecidas y cuidadas parece ser el principal acierto. Comprender la diversidad cultural y ambiental es fundamental. Las respuestas en las diferentes nacionalidades nos muestran diferencias que enriquecen el diálogo y subrayan la importancia de aplicar el enfoque intercultural. 
El debate irresuelto entre autonomías indígenas y centralismo institucional abre a su vez la necesidad de plantearse el aterrizaje de políticas públicas interculturales. Además acentúa la necesidad de definir en el país los mecanismos para viabilizar una estructura que respondan a los planteamientos constitucionales sobre la plurinacionalidad. El Estado como garante de derechos se mantiene en deuda con los pueblos indígenas frente a quienes se continúa ejerciendo un poder colonial, acciones de despojo, opresión y violencia. De todo esto, se pone sobre la mesa una discusión urgente sobre el cuidado de la vida, de los recursos limitados de la naturaleza y sobre la riqueza de las culturas ancestrales, su sabiduría y sus formas de organización, de las cuales se pueden aprender lecciones que apuntan a la necesidad de organizarnos como sociedades desde lógicas que prioricen el bien-estar y no la acumulación, y preparen a la humanidad para enfrentar al cambio climático el deterioro de la institucionalidad del Estado-nación. 


\section{BIBLIOGRAFÍA}

Asamblea Mundial por la Amazonía, Campaña Mundial frente a impactos COVID-19 en pueblos indígenas, afrodescendientes y amazónicos, 2020. Disponible en: $\quad$ https://www.forosocialpanamazonico.com/campanamundial-frente-a-impactos-covid-19-en-pueblos-indigenas-afrodescendientes-yamazonicos/[Fecha de consulta: 17 de septiembre de 2020]

Amazon Frontlines, Acción urgente para proteger a los pueblos indígenas de COVID-19 en Ecuador, marzo de 2020. Disponible en: https://www.amazonfrontlines.org/chronicles/accion-urgente-para-proteger-a-lospueblos-indigenas-de-covid-19-en-ecuador/ [Fecha de consulta: 7 de septiembre de 2020]

Aparicio Wilhelmi, M., "Estado, organización territorial y constitucionalismo plurinacional en Ecuador y Bolivia. ¿Una década ganada?", en Revista d'estudis autonòmics i federals, núm. 27, 2018, p. 121 (p. 118-146).

Barrera, M., "Respuestas comunitarias de los Territorios de Vida Ecuador a la Emergencia", en Aldea, 21 de mayo de 2020. Disponible en: http://www.fundacionaldea.org/noticiasaldea/c5ns2s6fkhk2le8jx4m7w8xz4pxaa5. [Fecha de consulta: 10 de septiembre de 2020].

Coordinadora de las Organizaciones Indígenas de la Cuenca Amazónica (COICA, 2020), "Fondo de Emergencia para la Amazonía". Disponible en: https://amazonemergencyfund.org/english/ [Fecha de consulta: 11 de septiembre de 2020]

Confederación de Nacionalidades Indígenas de la Amazonía Ecuatoriana, (CONFENAIE). Entrevista, Andrés Tapia, responsable de comunicación (julio de 2020).

Confederación de Nacionalidades Indígenas del Ecuador, CONAIE (junio, 2020). COMUNICADO "Ante la grave situación de los indígenas del Ecuador por el COVID-19". Disponible en: https://conaie.org/2020/06/18/covid19//Fecha de consulta: 26 de septiembre de 2020]

CEPAL, Comisión Económica para América Latina y El Caribe. Los pueblos indígenas de América Latina -Abya Yala y la Agenda 2030 para el Desarrollo Sostenible 2020. Disponible en: https://www.cepal.org/es/publicaciones/45664pueblos-indigenas-america-latina-abya-yala-la-agenda-2030-desarrollosostenible [Fecha de consulta, 22 de septiembre de 2020].

Comisión Interamericana de Derechos Humanos (CIDH). Res. 01/20. "Pandemia y Derechos Humanos en las Américas". Disponible en: https://www.oas.org/es/cidh/decisiones/pdf/Resolucion-1-20-es.pdf [Fecha de cosnulta: 30 de mayo de 2020] 
Charity, S., Dudley, N., Oliveira, D. and S. Stolton. Living Amazon Report 2016: A regional approach to conservation in the Amazon, WWF Living Amazon Initiative, Brasilia and Quito, 2016.

El Universo, "Río Bobonaza se lleva 30 casas de Sarayaku y el coronavirus llega a sus dominios", marzo de 2020. Disponible en: https://www.eluniverso.com/noticias/2020/06/14/nota/7872525/rio-bobonaza-selleva-30-casas-sarayaku-coronavirus-llega-sus [Fecha de consulta: 9 de septiembre de 2020].

Fernández, M. A., Marcos, J., "La vida a lomos de la Amazonía menguante", en EsGlobal, 13 de octubre de 2020. Disponible en: https://www.esglobal.org/lavida-a-lomos-de-la-amazonia-menguante/

Esposto, R. H., \& Holas, S., "Rodolfo Kusch: hacia una condición postcolonial pensada desde categorías epistemológicas situadas", en Dissidences (Hispanic Journal of Theory and Criticism), 4/5, 2008.

Fondo para el desarrollo de los pueblos indígenas de América Latina y el Caribe (FILAC), "El Relator Especial de las Naciones Unidas sobre los Derechos de los Pueblos Indígenas pide que se haga aportaciones sobre los efectos del COVID19 en los derechos de los Pueblos Indígenas". Disponible en: https://www.filac.org/wp/comunicacion/filac-informa/el-relator-especial-de-lasnaciones-unidas-sobre-los-derechos-de-los-pueblos-indigenas-pide-que-sehaga-aportaciones-sobre-los-efectos-del-covid-19-en-los-derechos-de-lospueblos-indigenas-2/ [Fecha de consulta: 1 de octubre de 2020]

Fundación Pachamama. Entrevista, Belén Páez, Directora. (Mayo-Junio, 2020).

Gálvez, D., López, V., Estudios Poscoloniales: Genealogías Latinoamericanas. Scielo, 21 de junio de 2018. Versión On-line, Santiago de Chile, Chile. Disponible en: https://scielo.conicyt.cl/scielo.php?script=sci arttext\&pid=S0719$\underline{36962018000100017}$

Grosfoguel, R., "Del extractivismo económico al extractivismo epistémico y al extractivismo ontológico: una forma destructiva de conocer, ser y estar en el mundo", en Tabula Rasa, núm. 24, enero-junio, Universidad Colegio Mayor de Cundinamarca-Bogotá, Colombia, 2016, p. 123-143.

Instituto Nacional de Estadísticas y Censos del Ecuador, INEC.

(2010) Censo de Población y Vivienda.

(2019) Encuesta nacional sobre relaciones familiares y violencia de género contra las mujeres.

Kush, R. G.,"Una lógica de la negación para comprender a América” y "La negación en el pensamiento popular", en Obras Completas, Tomo II, Editorial Fundación Ross, Rosario, Argentina, 2000. 
López A., V., Espíndola, F., Calles, J. y Ulloa, J., Atlas Amazonía Ecuatoriana Bajo Presión, EcoCiencia, Quito-Ecuador, 2013.

Organización Mundial de la Salud (OMS)

(2013) La salud de los pueblos indígenas y afrodescendientes en América Latina". Boletín estadístico.

(2020) Pueblos y nacionalidades en el centro: la estrategia nacional para promocionar la salud en tiempos de pandemia.

Ministerio de Salud Pública de Ecuador, "MSP fortalece atención de primer nivel a Pueblos y Nacionalidades Indígenas", septiembre de 2020. Disponible en https://www.salud.gob.ec/msp-fortalece-atencion-de-primer-nivel-a-pueblos-ynacionalidades-indigenas/ [fecha de consulta, 29 de septiembre de 2020] Mongabay Latam.

"Ecuador: la rotura del oleoducto OCP revela el impacto de construir en zonas de alto riesgo", mayo de 2020Disponible en: https://es.mongabay.com/2020/05/ecuador-rotura-oleoducto-ocp-petroleo/ [fecha de consulta, 26 de septiembre de 2020].

"Covid-19 en Ecuador: indígenas enfrentan el riesgo de la automedicación", julio de $2020 . \quad$ Disponible en https://es.mongabay.com/2020/07/covid-19-ecuador-indigenasautomedicacion/ [fecha de consulta: 1 de octubre de 2020]

"Tribunal obliga al gobierno de Ecuador a proteger a la población indígena waorani durante la pandemia" (julio, 2020). Disponible en https://es.mongabay.com/2020/07/ecuador-tribunal-obliga-al-gobierno-aproteger-a-la-poblacion-indigena-waorani-covid-19/ [fecha de consulta, 19 de septiembre de 2020].

"Alerta en la Amazonía ecuatoriana: madereros ilegales arrasan en medio de la pandemia", Septiembre de 2020. Disponible en: https://es.mongabay.com/2020/09/tala-ilegal-en-ecuador-amazoniapueblos-indigenas/ [Fecha de consulta, 11 de octubre de 2020]

Nemonte Nenquimo, "Una carta desde la Amazonía: uno destruye lo que no entiende. La líder ambiental del pueblo waorani lanza un aviso a los presidentes de los nueve países amazónicos", en El País, 12 de Octubre de 2020.

Naciones Unidas Ecuador, "Pueblos y nacionalidades en el centro: la estrategia nacional para promocionar la salud en tiempos de pandemia", mayo 2020. Disponible en: https://ecuador.un.org/es/45880-pueblos-y-nacionalidades-en-elcentro-la-estrategia-nacional-para-promocionar-la-salud-en [Fecha de consulta, 19 de septiembre de 2020] 
Naranjo, P., Escaleras, R., "La medicina tradicional en el Ecuador", en Memorias de las Primeras Jornadas Ecuatorianas de Etnomedicina Andina, Universidad Andina Simón Bolívar / Corporación Editora Nacional, Quito,Ecuador, 1995.

Organización Internacional del Trabajo

(2020) OIT: 55 millones de personas indígenas en América Latina y el Caribe afectados por alta vulnerabilidad a la crisis de la COVID-19. Disponible en: https://www.ilo.org/americas/sala-deprensa/WCMS 746960/lang--es/index.htm [Fecha de consulta: 12 de septiembre de 2020).

(2020) Aplicación del Convenio sobre pueblos indígenas y tribales núm. 169 de la OIT: Hacia un futuro inclusivo, sostenible y justo. Disponible en: https://www.ilo.org/global/publications/books/WCMS 735627/lang-es/index.htm [Fecha de consulta: 12 de septiembre de 2020).

República del Ecuador:

(2008) Constitución de la República del Ecuador

(2009) Ley de Seguridad Pública y del Estado

(2010) Reglamento a la Ley de Seguridad Pública y del Estado. (Última modificación, 14 de julio de 2017).

Vallejo, I., Álvarez, K., "La pandemia del Coronavirus en la Amazonía ecuatoriana: vulnerabilidades y olvido del Estado" en Cadernos de Campo (São Paulo, online) | vol.29, n.1 | p.95-110| USP 2020

Sánchez, L., "Difracciones de género y traducción: hacia otra cartografía de saberes situados", en Studies, 7(2), 2012, p. 129-143.

Servicio Nacional de Gestión de Riesgos y Emergencias. "Resoluciones COE Nacional 14 de marzo 2020". Diponsible en https://www.gestionderiesgos.gob.ec/resoluciones-coe-nacional-14-de-marzo2020/ [Fecha de consulta 2 de dicembre de 2020]

Revista Times (Septiembre, 2020). "The 100 most influential people of 2020. Nemonte Menquimo", Disponible en: https://time.com/collection/100-mostinfluential-people-2020/5888337/nemonte-nenquimo/ [Fecha de consulta, 27 de septiembre de 2020] 